\title{
Geotechnical characteristics of polystyrene treated sand
}

\author{
Boyeong Yoon ${ }^{1}$, Jang-un $\mathrm{Kim}^{1}$, Jihwan Lee ${ }^{1}$, and Woojin Lee ,"* $^{1, *}$ \\ ${ }^{1}$ Korea University, School of Civil, Environmental, and Architectural Engineering, Seoul, Korea
}

\begin{abstract}
Many polymeric materials are recently used in geotechnical practice for enhancing the engineering properties of soils. Among the various polymers, this study aims at investigating the geotechnical properties of silica sand coated with polystyrene(PS), which is rarely studied in geotechnical engineering. The polystyrene coated sand was prepared by polymerizing styrene monomer on the surface of silanized sand with median diameter of $0.467 \mathrm{~mm}$. Testing specimens were prepared at 3 different initial relative densities (30, 50 and $70 \%$ ) by air pluviation. Comprehensive experiments, including one-dimensional compression test with bender elements and triaxial test, were performed to observe the change in geotechnical properties due to the coating of PS on sand surface. The results demonstrate that the adsorbed polymer plays different roles according to strain levels. At very small strain, the polymer on the sand surface may increase the interparticle contact area by applying additional adhesion force between soil particles, leading to an increase in $G_{\max }$. However, with an increase in strain level, the polymer will act as the lubricant between sand particles; therefore, the coated sand can show increased compression index and decreased friction angle.
\end{abstract}

\section{Introduction}

Polymer, which composed of many repeated subunits, shows broad range of properties which makes it possible to play various roles in human life [1]. In geotechnical engineering, polymers have been used as the nontraditional additives for the artificial stabilizations of soft ground, sand fixing effect, polymer grouting, and to compose artificial floor surfaces. Recent studies on the use of polymers in engineering area focused on reducing toxicity of conventional polymers, developing novel polymers by industrial wastes [2] and applying polyurethane resin to reduce seismic damage [3]. Likewise, interest in the use of polymers in geotechnical engineering have been increased recently; however, there is the lack of understanding in the role of polymers on the behaviour of soils. Therefore, this study aims at investigating behaviours of polymer-coated sand and reveal the role of polymer. Polystyrene was chosen as coating polymer because it is one of the most widely used plastics, and various geotechnical tests have been performed in this study.

\section{Experimental Procedure}

\subsection{Materials}

The success of encapsulation by monomer polymerization on the surface of sand particles depends on the nature of particle surface. Therefore, to facilitate the electrostatic or hydrophobic interactions between the polymer and the surface of sand particles, coupling agent was needed [4].
Crushed sand with median diameter $\left(\mathrm{D}_{50}\right)$ of 0.467 $\mathrm{mm}$ was used as substrate material. MPS (3(trimethoxysilyl) propyl methacrylate, ESL8370, Esung Materials, Korea) was used for grafting coupling agent. The initiator, NaSS (Sodium p-styrenesulfonate, Sigma Aldrich) and the buffer agent, KPS (Potassium persulfate, Sigma Aldrich) was used as received. Figure 1 shows chemical structure of polystyrene, which contains many carbon elements.

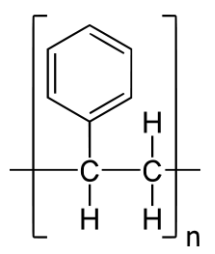

Fig. 1. Chemical structure of polystyrene used for coating material in this study

\subsection{Synthesis of polymer modified sand}

\subsubsection{Synthesis procedure}

Sands were submerged to solution of $3 \% \mathrm{H}_{2} \mathrm{O}_{2}$ and stirred for every 3 hours for 24 hours to eliminate any organic materials. After drying at oven, sand was submerged at ethanol with MPS and stirred for 3 days at room temperature. Following [5], ethanol and water mixture $(35 / 36, w / w)$ was prepared under nitrogen gas. KPS and NaSS were added to the suspension and then the solution was heated to $70^{\circ} \mathrm{C}$. After temperature converged to stable phase, styrene monomer was charged to initiate

\footnotetext{
* Corresponding author: woojin@korea.ac.r
} 
polymerization at the surface of sand particles. The container was allowed to stand for a day so that the reaction could sufficiently take place. The polymer treated sand was washed with ethanol for 3 times and dried at oven at $45^{\circ} \mathrm{C}$.

\subsubsection{Surface analysis}

To assure polymerization process on the surface of sand, polymer treated sand particles were viewed by both microscope (Nikon, AZ100) and FESEM/EBSD (Hitachi, S-4300SE).

\subsection{Specimen preparation}

Index properties, including specific gravity, maximum void ratio $\left(\mathrm{e}_{\max }\right)$ and minimum void ratio $\left(\mathrm{e}_{\min }\right)$, of polystyrene coated sand (treated sand) and untreated sand are summarized in Table 1. Because polystyrene adsorbed onto sand surface are mainly composed of carbon and hydrogen element, which is lighter than silica particles $\left(\mathrm{SiO}_{2}\right)$, treated sand has lower specific gravity than untreated sand. Treated sand shows greater maximum and minimum void ratios than untreated sand. It may be attributed to the fact that the modified sand surface due to the presence of polystyrene results in the different contact behaviour between sand particles.

Table 1. Basic properties of treated and untreated sand.

\begin{tabular}{|c|c|c|}
\hline Type & $\begin{array}{c}\text { Treated } \\
\text { sand }\end{array}$ & $\begin{array}{c}\text { Untreated } \\
\text { sand }\end{array}$ \\
\hline Specific gravity, $\mathrm{G}_{\mathrm{s}}$ & 2.562 & 2.640 \\
\hline Maximum void ratio, $\mathrm{e}_{\max }$ & 1.088 & 1.035 \\
\hline Minimum void ratio, $\mathrm{e}_{\min }$ & 0.765 & 0.655 \\
\hline
\end{tabular}

One-dimensional consolidation test with bender elements was performed to observe both compressibility and small strain stiffness of treated and untreated sands. Vertical effective stress, ranging from 7 to $448 \mathrm{kPa}$, was applied, and the settlement and shear waves were measured at the end of each loading step. The shear wave was generated to source bender element by function generator (33210A, Agilent), with a square wave with amplitude $=10 \mathrm{~V}$ and frequency $=20 \mathrm{~Hz}$. The receiver bender was connected to a filter amplifier (3364, KrohnHite), with high pass frequency $=100 \mathrm{~Hz}$ and low pass filter $=200 \mathrm{kHz}$, and input gain $=10 \mathrm{~dB}$. The signals were shown by oscilloscope (DOS5014A, Agilent), and the shear wave determined by the digitized signal as recorded by oscilloscope [6]. The tip-to-tip distance (i.e. the distance from tip of receiver bender element to tip of source bender element) was used as travel distance [6]. The measured shear wave velocity can be expressed according to: [7]

$$
V_{s}=A F_{e}\left(\frac{\sigma_{0}^{\prime}}{1 k P a}\right)^{\beta}
$$

where $F_{e}$ homogenization factor and is function of void ratio, e. Maximum shear modulus $\mathrm{G}_{\max }$ can be calculated according to:

$$
G_{\max }=\rho\left(V_{s}\right)^{2}
$$

Triaxial test was performed to observe large strain friction angle of treated and untreated sands. The confining stress was selected to be 100, 200 and $300 \mathrm{kPa}$. The loading strain rate was $0.5 \% / \mathrm{min}$, and test ended when strain reached $30 \%$. For both consolidation and triaxial tests, treated and untreated sand specimen were prepared by air-pluviation method to have initial relative density (DR) of 30, 50 and $70 \%$.

\section{Test results}

\subsection{Surface analysis}

Figure 2(a) shows microscope image of treated sand particle. White coloured-nontypical material was observed, which is believed to be polystyrene. For further clarification, figure 2(b) shows the SEM image of same particle. EDX result of the white coloured-nontypical material is summarized in Table 2. Carbon element, which is the main component of polystyrene, was detected. Therefore, it can be confirmed that polymerization of styrene occurred at the surface of sand particle.



(a)

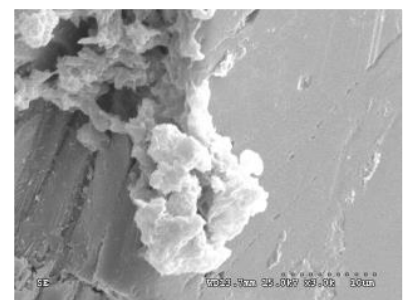

(b)
Fig. 2. (a) microscope image and (b) SEM image of treated sand

Table 2. Volumetric composition of the treated particles near white coloured-nontypical material.

\begin{tabular}{|c|c|c|c|}
\hline & $\mathbf{C}$ & $\mathbf{O}$ & $\mathbf{S i}$ \\
\hline \% element & 83.33 & 12.61 & 3.57 \\
\hline
\end{tabular}

\subsection{One-dimensional consolidation test with bender element}

\subsubsection{Compressibility}

From the settlement data, which was measured at the end of each loading step, the axial strain $\left(\varepsilon_{\mathrm{v}}\right)$ was calculated and plotted as the function of applied vertical stress $(\sigma)$ in 
Figure 2. Figure 2 demonstrates that the treated sand shows higher compressibility than untreated sand regardless of initial relative density. It is widely known that the compressibility is greatly influenced by initial void ratio $\left(\mathrm{e}_{0}\right)$ [8]. Also, the void ratio contains information about particle distribution. To observe compressibility with initial state of specimen, each compressibility index and initial void ratio was summarized at table 3 . Treated sand has higher $\mathrm{e}_{0}$ indicating that specimen in tested relative density range were in loose state. However, at similar $\mathrm{e}_{0}(\mathrm{DR}=70 \%$ for treated sand and $\mathrm{DR}=50 \%$ for untreated sand) treated sand showed higher compressibility. This demonstrates that the polymer attached on the sand surface not only form loose packing state of soil but also affects additional compressibility due to the change in contact behaviour between sand particles. This would be further analysed with the result of triaxial test.

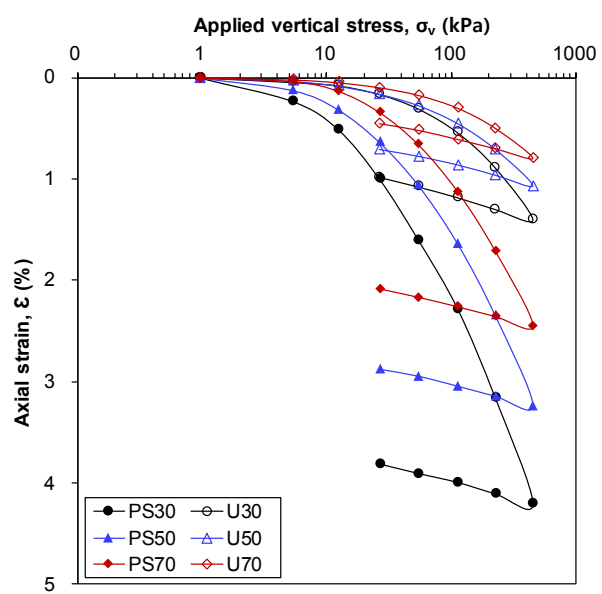

Fig. 3. Void ratio - stress graph of treated and untreated sand: bold symbols $=$ treated sand; open symbols $=$ untreated sand

Table 3. Compressibility index $\left(\mathrm{C}_{\mathrm{c}}\right)$ and initial void ratio $\left(\mathrm{e}_{0}\right)$ of Treatedand untreated sand

\begin{tabular}{|c|c|c|c|c|}
\hline \multirow{2}{*}{$\begin{array}{c}\text { Relative density, } \\
\text { DR (\%) }\end{array}$} & \multicolumn{2}{|c|}{ Treated sand } & \multicolumn{2}{c|}{ Untreated sand } \\
\cline { 2 - 5 } & $\mathbf{e}_{\mathbf{0}}$ & $\mathbf{C}_{\mathbf{c}}$ & $\mathbf{e}_{\mathbf{0}}$ & $\mathbf{C}_{\mathbf{c}}$ \\
\hline 30 & 0.989 & 0.064 & 0.920 & 0.028 \\
\hline 50 & 0.925 & 0.058 & 0.844 & 0.018 \\
\hline 70 & 0.860 & 0.041 & 0.770 & 0.014 \\
\hline
\end{tabular}

\subsubsection{Maximum shear modulus, $G_{\max }$}

From the measured shear wave velocity, $G_{\max }$ was calculated by equation (2). Figure 4 shows the comparison of $G_{\max }$ of treated and untreated sand at three different initial relative densities. Because the contact area between sand particles increases with applied stress, $G_{\max }$ increases with vertical stress. In addition, the higher DR indicates particles are in dense condition (i.e. higher coordination number), therefore $G_{\max }$ increases with $D R$.

Figure 4 also shows that the treated sand shows higher $\mathrm{G}_{\max }$ than untreated sand. Generally, $\mathrm{G}_{\max }$ is a function of void ratio at constant stress and $G_{\max }$ decreases with increase of void ratio. To compare $G_{\max }$ solely with particle contact effect, $\mathrm{G}_{\max }$ measured at vertical stress $\approx$ $224 \mathrm{kPa}$ at different DR are plotted with void ratio for treated and untreated sand (Figure 5). At the similar void ratio, the treated sand shows higher $G_{\max }$ than untreated sand, which indicates treated sand has higher contact area $[9,10]$. To examine the particle contact morphologies, additional SEM was performed. Figure 6 shows SEM image of treated sand after the consolidation test with bender elements. From the image, it can be considered that particles are clanged together due to polymer on the surface. Generally, it is known that polymer units have relative mobility at the interfaces[11, 12]. In other words, polymer chains on a substrate can be transferred on the other side of substrates, and this mobility depends on load, loading ratio, temperature and others. Due to this nature, polymer on the surface of treated sand has transferred to other particles foaming thin films which results in increase of interparticle contact area. Even if treated sand has lower void ratio, the increased interparticle contact area lead higher $\mathrm{G}_{\max }$ compared with untreated sand.

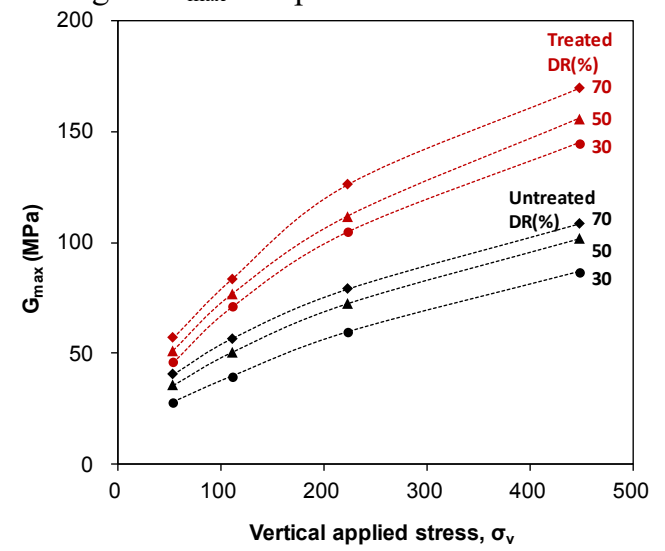

Fig. 4. Maximum shear modulus $\left(\mathrm{G}_{\max }\right)$ - vertical applied stress of treated and untreated sand

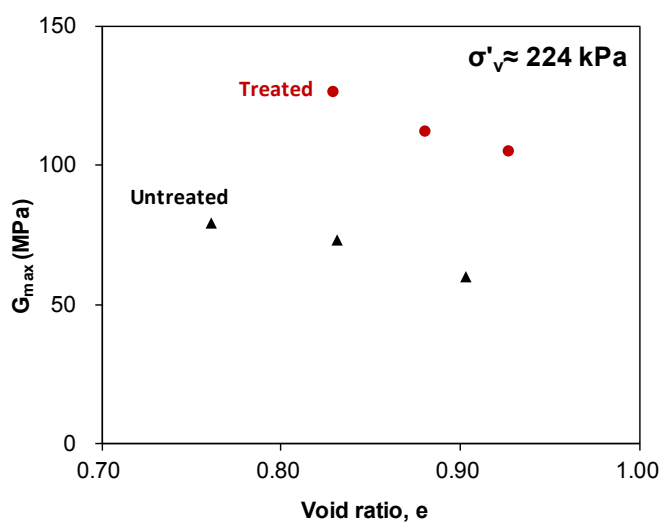

Fig. 5. $\mathrm{G}_{\max }$ - void ratio graph at vertical applied stress $224 \mathrm{kPa}$ 


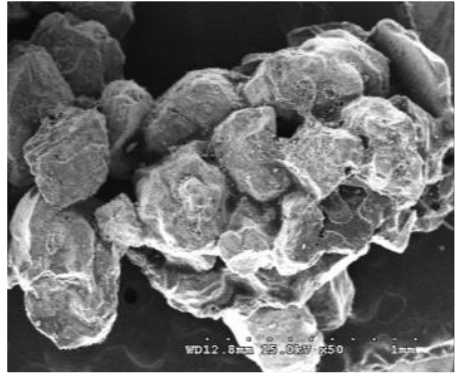

Fig. 6. SEM image of treated sand particle after one-dimensional consolidation test with bender elements performed

\subsection{Triaxial compression test}

Figure 7 shows triaxial test results of both untreated and treated sands at DR $=70 \%$. Untreated sand shows clear peak status while treated sand does not. This signify that treated sands show dilative behaviour where contractive behaviour prevails at untreated sand. From the result of triaxial test, peak friction angle $\left(\phi_{\text {peak }}\right)$ and residual friction angle (friction angle at strain $=28 \%, \phi_{\text {residual }}$ ) at each DR were calculated and summarized at table 4 . Generally peak friction angle satisfies following equation, $\phi_{\text {peak }}=$

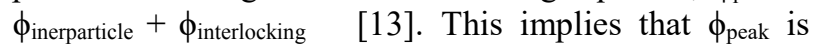
affected by friction characteristics of particles ( $\left.\phi_{\text {interparticle }}\right)$ and also volumetric change effect ( $\phi$ interlocking), in other words dilatancy. For treated sand specimen, there would be three contact types: (1) sand-to-sand contact (2) sandto-polymer contact and (3) polymer-to-polymer contact. Compared with polymer-to-polymer contact where relative mobility affects to friction property, polymer does not affect pure sand particles. Rather modified surface let particles slide easily. Consequently, the interparticle friction of treated particle would be smaller than that of untreated particle. Also as polymer on the surface works as lubricants for particles to slide, $\phi_{\text {interlocking of treated }}$ particle is smaller than untreated particles showing contractive behaviours. Therefore, treated sand can be more compressible than untreated sand which matches the result of $1 \mathrm{D}$-consolidation test.
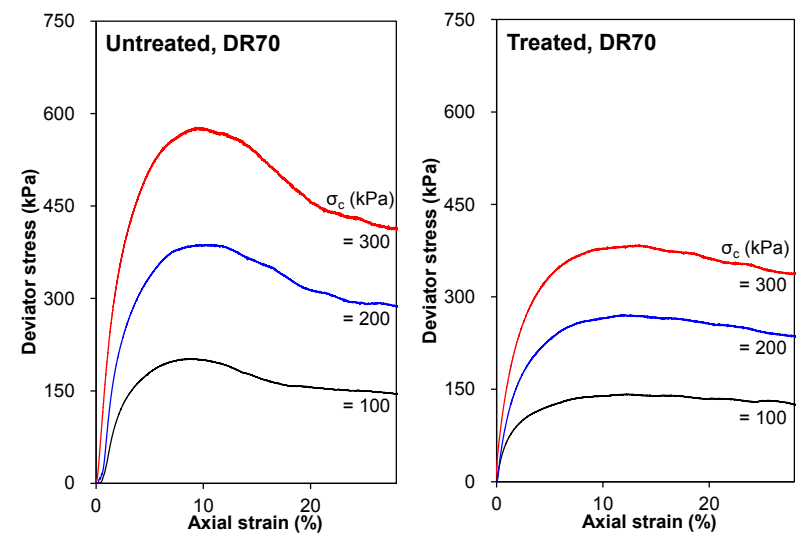

Fig. 7. Results of triaxial test
Table 4. Peak and residual friction angle of treated and untreated sand at each relative density

\begin{tabular}{|c|c|c|c|c|}
\hline & $\begin{array}{c}\text { DR } \\
(\%)\end{array}$ & $\mathbf{e}_{0}$ & $\begin{array}{c}\Phi_{\text {peak }} \\
\left({ }^{\circ}\right)\end{array}$ & $\begin{array}{c}\Phi_{\text {residual }} \\
\left({ }^{\circ}\right)\end{array}$ \\
\hline \multirow{3}{*}{$\begin{array}{c}\text { Treated } \\
\text { sand }\end{array}$} & 30 & - & - & - \\
\hline & 50 & 0.9265 & 20.98 & \multirow{2}{*}{20} \\
\hline & 70 & 0.8624 & 22.21 & \\
\hline \multirow{3}{*}{$\begin{array}{l}\text { Untreated } \\
\text { sand }\end{array}$} & 30 & 0.9227 & 26.74 & \multirow{3}{*}{24} \\
\hline & 50 & 0.8453 & 28.42 & \\
\hline & 70 & 0.7696 & 29.47 & \\
\hline
\end{tabular}

\section{Conclusion}

Polymerized sand was synthesized by following $\mathrm{Gu}$ et al. (2004), and confirmed the polymer on the surface by performing FESEM/EDSB.

One dimensional consolidation test with bender elements and triaxial test were performed to observe behaviour of treated and untreated sand on different strain ranges. Specimen were prepared by air-pluviation method at 3 different relative densities in dry condition. It is concluded that polymer on the surface of sand plays different roles depending on strain range.

It is shown that treated sand has higher maximum shear modulus, $\mathrm{G}_{\max }$, even though treated sand was at loose state. This would be due to relative mobility of polymer which transfer the chain to other sand particles, increasing interparticle contact area and interparticle contact number.

However, at large strain, polymer at the surface rather works as lubricants and particles slide much easier than untreated sand. Accordingly, interparticle friction angles gets smaller and interlocking effect gets smaller. Finally treated sand has high compressibility than untreated sand.

This research was supported by Basic Science Research Program through the National Research Foundation of Korea(NRF) funded by the Ministry of Science, ICT \& Future Planning (2018R1A2B6000973).

\section{References}

1. N. G. McCrum, C. Buckley, C. B. Bucknall and C. Bucknall, Principles of polymer engineering (Oxford University Press, USA,1997)

2. Y. Zang, W. Gong, H. Xie, Z. Du, B. Liu and H. Chen, Plastics, Rubber and Composites, 45, 270-276 (2016)

3. I. Golpazir, A. Ghalandarzadeh, M. K. Jafari and M. Mahdavi, Constr Build Mater, 118, 104-115 (2016)

4. E. Bourgeat-Lami and J. Lang, J. Colloid Interface Sci., 197, 293-308 (1998)

5. S. Gu, T. Kondo and M. Konno, J. Colloid Interface Sci., 272, 314-320 (2004)

6. J.-S. Lee and J. C. Santamarina, J Geotech Geoenviron, 131, 1063-1070 (2005)

7. J. C. Santamarina, A. Klein and M. A. Fam, J SOIL SEDIMENT, 1, 130-130 (2001) 
8. J. K. Mitchell and K. Soga, Fundamentals of soil behavior (John Wiley \& Sons New York,2005)

9. C. Lee, Q. H. Truong and J.-S. Lee, Canadian Geotechnical Journal, 47, 763-774 (2010)

10. H. Choo, J. Larrahondo and S. Burns, Journal of GeotechnicalGeoenvironmental Engineering, 141, 04014077 (2014)

11. S. Bistac, A. Ghorbal and M. J. P. i. o. c. Schmitt, 55, 345-354 (2006)

12. ]H. Zeng, N. Maeda, N. Chen, M. Tirrell and J. J. M. Israelachvili, 39, 2350-2363 (2006)

13. T. W. Lambe, R. V. Whitman, J Jhon Wiley and Sons, (1969) 